\title{
Physico-Chemical Properties, Functional Properties, and Chemical Compositions Of Ziziphus Mauritiana (Jujube) Seed Oil
}

\author{
Alawode Rahmatallah Adenike*1, Bernard 0 Odey ${ }^{2}$, Muhammed Dauda ${ }^{1}$, Adegbola Gbolagade Adeyemi ${ }^{1}$ \\ and Richard 0 Babatunde ${ }^{3}$
}

${ }^{1}$ Forestry Research Institute of Nigeria -Southern Guinea Research Station Mokwa, Nigeria

${ }^{2}$ Trial Afforestation Research Station, Forestry Research Institute of Nigeria (FRIN), Afaka-Kaduna State, Nigeria

${ }^{3}$ Agricultural Extension and Management, Federal College of Forestry, Ibadan, Nigeria

*Corresponding author: Alawode Rahmatallah Adenike, Forestry research institute of Nigeria Southern Guinea Research station Mokwa, Nigeria.

Received Date: October 6, 2020

Published Date: November 04, 2020

\begin{abstract}
This study investigated the physico-chemical properties, functional properties, and chemical compositions of Ziziphus mauritiana (Jujube) seed oil using standard analytical methods. The results indicated that Jujube seed oil exhibited swelling capacity of $6.10 \pm 0.23 \%$, water absorption capacity of $20.22 \pm 0.45$, oil absorption capacity of $18.53 \pm 0.43 \%$, bulk density of $0.583 \pm 0.01 \%$, gelatinization temperature of $72.34 \pm 1.67 \%$, foaming stability of $56.36 \pm 0.12 \%$, foaming capacity of $8.29 \pm 0.02 \%$, emulsion ability of $30.21 \pm 0.13$ and emulsion stability of $27.62 \pm 0.89$. the oil also shows specific gravity of $0.913 \pm 0.08 \mathrm{Kg} / \mathrm{L}$, acid value of $2.27 \pm 0.17 \mathrm{mgKOH} / \mathrm{g}$, saponification value of $192.40 \pm 9.98 \mathrm{mgKOH} / \mathrm{g}$, peroxide value of $2.22 \pm 0.12$ $\mathrm{mmol} / \mathrm{Kg}$, free fatty acid of $1.14 \pm 0.09 \%$ and iodine value of $66.74 \pm 4.29 \mathrm{~g} / 100 \mathrm{~g}$. a total of 19 chemical compound were identified from Z. mauritiana seed oil using GC-MS. The most abundant compound N-[3-[N-Aziridyl] propylidene] hexyl amine with retention time (RT) and peak area (PA) of $5.523 \mathrm{~s}$ and 38.32 respectively, followed by Benzeneethanamine, 4-methoxy-2-Butyne-1,4-diol with RT and PA of 9.833\% and 7.29 respectively while terebic acid, n-Capric acid and oxalic acid were among the least abundant compounds identified. In conclusion, the seed oil of Ziziphus mauritiana (Jujube) exhibited a desirable characteristic for nutritional and industrial application.
\end{abstract}

Keywords: Physio-chemical; Functional properties; Chemical compositions; Ziziphus mauritiana; Seed oil

\section{Introduction}

The United Nations projected that by 2050, the world population will reach 9.6 billion [1]. In order to meet up the increase demand due to population growth, oil crops production has to increase by 133 million tones to reach 282 million tonnes [2]. The major oil crops; soybean, sunflower, rape and oil palm, rape, and sunflower account for $83 \%$ of the global production [3], with temperate region; Europe and America accounting for about $60 \%$ of the global oil seed production while tropical regions such as Africa, Malaysia, and Indonesia account for less than $5 \%$ of the global oil seed production [4]. Majority of production from these tropical regions are cotton, coconut, oil palm, groundnut oil [2]. However, a pectoral of traditional oil seeds in tropical Africa remain underexploited and underutilized owing to the inadequate knowledge of the functional and nutritional properties as well as the economic values of the 
seed oil. One of such traditional oil seed is the Jujube seed (Ziziphus mauritiana) a member of Rhamnaceae family.

Ziziphus mauritiana Lam (Z. mauritiana) is a tropical fruit tree with oil producing seed, it is commonly known as Jujube or magarya (Northern part of Nigeria) and grows in arid and semiarid part of the tropics [5]. Ziziphus mauritiana leaves, fruit and seed commonly used by Nigerian traditional herbalist for treatment of various ailment including; sexual deficiency, diabetes, obesity, fever, cough, convulsion, epilepsy, diarrhea, ulcers, digestive and urinary discomfort, sleep disorders, burning sensations skin rashes and ulcers [6]. Various parts of Ziziphus mauritiana have also received scientific validation of its immunomodulatory [7], free radical antagonist [8], anticancer [9], anti-diarrhoeal [10] hypoglycemic [11], antiulcer [12], antimicrobial [13], antimycobacterial and antiplasmodial [14] activities.

However, despite the medicinal properties of Ziziphus mauritiana, its seed is less explored, underutilized and are often discarded as a waste. However, recent studies have indicated that the less underutilized seed could serve as a rich source of nutrient thus contribute to solving the problems of malnutrition. Our previous study shows that Ziziphus mauritiana (Jujube) seed as a protein source in the diet promote growth performance and stabilized hematology, lipid profile and serum chemistry profile of Rattus norvergicus [13]. To our knowledge, there are limited scientific reports on the physicochemical, functional and chemical composition of the oil produced from the seeds of Ziziphus mauritiana. This study was therefore carried out to determine the physicochemical, functional and chemical composition oil extracted from Ziziphus mauritiana seeds.

\section{Materials and Methods}

\section{Sample collections}

Matured fruits of Ziziphus mauritiana fruits were picked directly from the trees in March 2017 from Barnawa area of Kaduna, Kaduna State. The sample was identified and authenticated at the herbarium unit of Department of Biological Sciences Ahmadu Bello University where existing voucher number of the specimen (No. 7072) was given.

\section{Sample preparation}

The fruits were macerated in water to remove the pulp and the seeds were rinsed in clean water. Thereafter the seeds were spread out, sun dried. The dried seeds were grounded and sieved through a mesh to obtain a fine powder which was stored in airtight container.

\section{Analysis of physicochemical properties}

Ziziphus mauritiana seed oil was analysed for physicochemical properties using standard procedures [15]. Specific gravity was evaluated using Specific Gravity Hydrometers (Fisher Scientific, Pittsburgh, PA). The saponification values were determined according to the American Oil Chemists Society method [15].
The peroxide value, acid value and iodine value were calculated following the AOCS standard method (Cd 8b-90), (Cd, 3d-63) and (Cd, 1c-85) respectively. Free fatty acid composition was analysed using Gas Chromatograph (QP5050, Shimadzu, Japan) following the AOCS (Ce 2-66) standard.

\section{Analysis of functional properties}

The standard analytical procedures for food analysis as described below were used.

Bulk density: Firstly, a dried and empty $10 \mathrm{~cm}^{3}$ measuring cylinder was weighed. The sample was filled gently into the weighed $10 \mathrm{~cm}^{3}$ measuring cylinder and then gently tapped at the bottom on a laboratory bench several times until there was no further diminution of the sample level after filling to the $10 \mathrm{~cm}^{3}$ mark. After this, the filled measuring cylinder was weighed and recorded [15]:

The bulk density $\left(\mathrm{g} / \mathrm{cm}^{3}\right)=$ Weight of sample $(\mathrm{g}) /$ Volume of sample $\left(\mathrm{cm}^{3}\right)$

Water/oil absorption capacity: From the ground sample, $1.00 \mathrm{~g}$ was weighed into a conical graduated centrifuge tube and 10 $\mathrm{cm}^{3}$ of water or oil was added to the weighed sample. A warring whirl mixer was used to mix the sample for $30 \mathrm{~s}$. The sample was allowed to stand at room temperature for $30 \mathrm{~min}$ and then centrifuged at $5000 \mathrm{rpm}$ for $30 \mathrm{~min}$. After then the mixed sample was transferred from the graduated centrifuge tube into a $10 \mathrm{~cm}^{3}$ measuring cylinder to know the volume of the free water or oil. The absorption capacity was expressed as grams of oil or water absorbed per gram of sample. Calculation; water/oil absorption capacity of the sample was calculated as:

(Total oil/water absorbed - free oil/water) $\times$ Density of oil/ water [15].

Foam capacity and stability: From the powdered sample, $2.00 \mathrm{~g}$ were weighed, blended with $100 \mathrm{~cm}^{3}$ of distilled water using warring blender (Binatone BLG- 555) and the suspension was whipped at $1600 \mathrm{rpm}$ for $5 \mathrm{~min}$. The mixture was then poured into a $100 \mathrm{~cm}^{3}$ measuring cylinder and its volume was recorded after 30 s. Foam capacity was expressed as percent increase in volume using the formula of AOAC [15].

Foam capacity $=\frac{\text { Volume after } \text { whipping }- \text { volume before whipping }}{\text { Volume before whipping }} \times 100$

The foam stability of the sample was recorded at 15, 30, 60 and $120 \mathrm{~s}$ after whipping to determine the foam stability (FS).

\section{Foam stability $=\frac{\text { Foam volume after time }}{\text { Initial foam volume }} \times 100$}

Gelatinization temperature: In triplicates, 5\% sample was suspended in test tubes, heated in a boiling water bath with continuous stirring and $30 \mathrm{~s}$ after gelatinization was visually noticed, the temperature of the samples was taken as the gelatinization temperature [16]. 
Emulsification capacity (EC): From the sample, $2.00 \mathrm{~g}$ of sample were blended with $25 \mathrm{~cm}^{3}$ of distilled water at room temperature for $30 \mathrm{~s}$ in a warring blender at $1600 \mathrm{rpm}$. After complete dispersion, $25 \mathrm{~cm}^{3}$ of vegetable oil was gradually added and the blending continued for another $30 \mathrm{~s}$. Then the mixture was transferred into a centrifuge tube and centrifuged at $1600 \mathrm{rpm}$ for 5 min. The volume of oil separated from the sample was read directly from the tube after centrifuging. Calculation: The emulsion capacity was expressed as the amount of oil emulsified and held per gram of sample:

\section{$\mathrm{X}$ Emulsion capacity $=\mathrm{X} / \mathrm{Y} \times 100$}

Where $\mathrm{X}=$ height of emulsified layer and $\mathrm{Y}=$ height of the whole solution in the centrifuge tube [15].

\section{Gas Chromatography mass spectrometry (GC/MS) analysis}

The GC/MS analysis of Ziziphus mauritiana seed oil was perform using GC-MS clarus 500 per kin Elmer system comprising an AOC20i auto sampler. "The instrument is equipped with a VF $5 \mathrm{~ms}$ fused silica capillary column of $30 \mathrm{~m}$ length, $0.25 \mathrm{~mm}$ diameter and 0.25 $\mu \mathrm{m}$ film thickness." The temperatures employed were; column oven temperature $80^{\circ} \mathrm{C}$, injection Temp $250^{\circ} \mathrm{C}$ at a pressure of $108.0 \mathrm{kPa}$, with total flow and column flow of $6.20 \mathrm{ml} / \mathrm{min}$ and $1.58 \mathrm{ml} / \mathrm{min}$, respectively. The linear velocity was $46.3 \mathrm{~cm} / \mathrm{s}$ and a purge flow of $3.0 \mathrm{ml} / \mathrm{min}$. The GC program ion source and interface temperature were $200.00{ }^{\circ} \mathrm{C}$ and $250.00{ }^{\circ} \mathrm{C}$, respectively, with solvent cut time of $2.50 \mathrm{~min}$. The MS program starting time was $3.00 \mathrm{~min}$ which ended at 30.00 min with event time of $0.50 \mathrm{~s}$, scan speed of 1666 $\mu \mathrm{l} / \mathrm{s}$, scan range 40-800 $\mathrm{u}$, and an injection volume of $1 \mu \mathrm{l}$ of the propolis extract (split ratio 10:1). The total running time of GC-MS was $30 \mathrm{~min}$. The relative percentage of the extract was expressed as percentage with peak area normalization as previously reported by Lawal et al. (2015).

Identification of the Components: Interpretation on the mass spectrum was conducted using the database of National Institute
Standard and Technology (NIST) having more than 62,000 patterns. The fragmentation pattern spectra of the unknown components were compared with those of known components stored in the NIST library. The relative percentage amount of each bio-component was calculated by comparing its average peak area to the total area.

\section{Results}

\section{Physicochemical Properties of Z. mauritiana seed}

The physicochemical properties of $Z$. mauritiana seed are presented in Table 1; Z. mauritiana seed showed specific gravity of $0.913 \pm 0.08 \mathrm{Kg} / \mathrm{L}$, acid value of $2.27 \pm 0.17 \mathrm{mgKOH} / \mathrm{g}$, saponification value of $192.40 \pm 9.98 \mathrm{mgKOH} / \mathrm{g}$, peroxide value of $2.22 \pm 0.12 \mathrm{mmol} /$ $\mathrm{Kg}$, free fatty acid of $1.14 \pm 0.09 \%$ and iodine value of $66.74 \pm 4.29$ g/100g.

\section{Functional Properties of Z. mauritiana seed}

The functional Properties of $Z$. mauritiana seed are presented in Table 2; the Z. mauritiana seed showed swelling capacity of $6.10 \pm 0.23 \%$, water absorption capacity of $20.22 \pm 0.45$, oil absorption capacity of $18.53 \pm 0.43 \%$, bulk density of $0.583 \pm 0.01 \%$, gelatinization temperature of $72.34 \pm 1.67 \%$, foaming stability of $56.36 \pm 0.12 \%$, foaming capacity of $8.29 \pm 0.02 \%$, emulsion ability of $30.21 \pm 0.13$ and emulsion stability of $27.62 \pm 0.89$.

\section{Gas chromatography and mass spectroscopy (GC-MS)}

The compound names, retention time and peak area of chemical compositions of Z. mauritiana seed oil using GC-MS are shown in Table 3: Z. mauritiana seed oil contains N-[3-[N-Aziridyl] propylidene] hexyl amine, Benzeneethanamine, 4-methoxy-2Butyne-1,4-diol, Terebic acid, Pentanoic acid, 4-methyl-, methylester, Hexadecanoic acid, methyl ester, 10-Undecynoic acid, 3-Dodecanol, Cyclopropane, Pentanoic acid, 2,6-Octadiene, Butane, 1,3,4-Thiadiazole, 2-amino-5-(heptylthio), 9-0xononanoic acid, D-Galactose, Isoxazolidine, 5-ethyl-2,4-dimethyl, 2-Phenyl-1,2propanediol, n-Capric acid, 1,3-Bis-t-butylperoxy-phthalan and oxalic acid.

Table 1: Physicochemical Properties of Z. mauritiana seed.

\begin{tabular}{|c|c|}
\hline Parameter & Z.mauritiana \\
\hline Specific gravity $(\mathrm{Kg} / \mathrm{L})$ & $0.913 \pm 0.08$ \\
\hline Acid value $(\mathrm{mgKOH} / \mathrm{g})$ & $2.27 \pm 0.17$ \\
\hline Saponification value $(\mathrm{mgKOH} / \mathrm{g})$ & $192.40 \pm 9.98$ \\
\hline Peroxide value $(\mathrm{mmol} / \mathrm{Kg})$ & $2.22 \pm 0.12$ \\
\hline Free fatty acid $(\%)$ & $1.14 \pm 0.09$ \\
\hline Iodine value $(\mathrm{g} / 100 \mathrm{~g})$ & $66.74 \pm 4.29$ \\
\hline
\end{tabular}

Data are Mean \pm SEM of triplicate determination.

Table 2: Functional Properties of Z. mauritiana seed.

\begin{tabular}{|c|c|}
\hline Functional properties & Value \\
\hline SC (\%) & $6.10 \pm 0.23$ \\
\hline WAC (\%) & $20.22 \pm 0.45$ \\
\hline
\end{tabular}




\begin{tabular}{|c|c|}
\hline OAC $(\%)$ & $18.53 \pm 0.43$ \\
\hline $\mathrm{BD}\left(\mathrm{g} / \mathrm{cm}^{3}\right)$ & $0.583 \pm 0.01$ \\
\hline $\mathrm{GT}(0 \mathrm{C})$ & $72.34 \pm 1.67$ \\
\hline $\mathrm{FS}(\%)$ & $56.36 \pm 0.12$ \\
\hline $\mathrm{FC}(\%)$ & $8.29 \pm 0.02$ \\
\hline $\mathrm{EA}(\%)$ & $30.21 \pm 0.13$ \\
\hline ES (\%) & $27.62 \pm 0.89$ \\
\hline
\end{tabular}

Key: Data are Mean \pm SEM of triplicate determination. SC: Swelling capacity, WAC: Water absorption capacity, OAC: Oil absorption capacity, BD: Bulk density, GT: Gelatinization temperature, FS: Foaming stability, FC: Foaming capacity, EA: Emulsion ability, ES: Emulsion stability.

Table 3: Chemical compositions of Z. mauritiana seed oil using Gas chromatography and mass spectroscopy (GC-MS).

\begin{tabular}{|c|c|c|c|}
\hline S.No & Compounds & Retention time (s) & Peak Area \\
\hline 1 & $\mathrm{~N}$-[3-[N-Aziridyl] propylidene] hexyl amine & 5.523 & 38.32 \\
\hline 2 & Benzeneethanamine, 4-methoxy-2-Butyne-1,4-diol & 9.833 & 7.29 \\
\hline 3 & Terebic acid & 30.77 & 0.72 \\
\hline 4 & Pentanoic acid, 4-methyl-, methyl-ester & 41.189 & 0.45 \\
\hline 5 & Hexadecanoic acid, methyl ester & 49.084 & 13.83 \\
\hline 6 & 10-Undecynoic acid & 54.716 & 1.93 \\
\hline 7 & 3-Dodecanol & 54.964 & 3.48 \\
\hline 8 & Cyclopropane & 55.906 & 1.69 \\
\hline 9 & Pentanoic acid & 60.024 & 3.18 \\
\hline 10 & 2,6-Octadiene & 61.335 & 1.61 \\
\hline 11 & Butane & 84.14 & 0.81 \\
\hline 12 & 1,3,4-Thiadiazole, 2-amino-5-(heptylthio) & 85.769 & 0.5 \\
\hline 13 & D-Galactose & 86.578 & 1.54 \\
\hline 14 & 9-Oxononanoic acid & 89.431 & 0.6 \\
\hline 15 & Isoxazolidine, 5-ethyl-2,4-dimethyl & 90.399 & 0.74 \\
\hline 16 & 2-Phenyl-1,2-propanediol & 92.619 & 0.59 \\
\hline 17 & n-Capric acid & 93.503 & 0.39 \\
\hline 18 & 1,3-Bis-t-butylperoxy-phthalan & 95.174 & 1.59 \\
\hline 19 & Oxalic acid & 98.493 & 0.49 \\
\hline
\end{tabular}

\section{Discussion}

Food functional properties are very important for the appropriateness of the diet, behavior of nutrients during food processing, storage and preparation because they affect the general quality of foods as well as their acceptability [17]. Bulk density which is a function of particle size was $0.583 \pm 0.01$ which is an indication that the particle size was high. This value is similar to the bulk density of $0.67 \pm 0.02$ reported for date palm fruit [16]. Increase in bulk density is desirable because it offers greater packaging advantage, as a greater quantity may be packed within a constant volume [18]. The water absorption capacity of $20.22 \pm 0.45$ recorded in this study is also similar to the $2.50 \pm 0.05$ reported for date palm fruit [16]. This water absorption capacity of Z. mauritiana seed is an indication of its heaviness and suitability as a drug binder and disintegrate in pharmaceuticals industrials [19]. The present study also indicated that had very higher gelatinization temperature of
$72.34 \pm 1.67 \%{ }^{\circ} \mathrm{C}$ which affects the time required for the cooking of food substances.

The fat absorption capacity (FAC) which is critical in determining the flavour retention in food materials was found to be $18.53 \pm 0.43 \%$. Emulsion stability (ES) was found to be $27.62 \pm 0.89 \%$ and is higher than $13.19 \pm 1.0 \%$ reported for Jack beans [20]. Emulsion stability is important for stabilization of additives in production of foods like soup and cakes. The higher value of foaming capacity (FC) and foaming stability (FS) of Z. mauritiana seed suggests its use as a whipping or aerating agent in food system [20].

A high saponification value $(192.40 \pm 9.98 \mathrm{mgKOH} / \mathrm{g})$ recorded in this study is similar to the saponification value of 197.80 recorded for Z. oenoplia seed oil [21], this high value could be attributed to high content of medium chain fatty acids (i.e., C16 and C18) in the seed oil. Furthermore, this high saponification value is a desirable property for production and manufacturing of shoe polish, alkyd 
resin, shampoo and liquid soaps [21]. The value recorded in this study is also similar to saponification values of soybean (189-195) and groundnut (187-196) as reported by Gunstone [22]. The acidity is an important parameter in determining the quality of the seed oil. The low levels of free fatty acids $(1.14 \pm 0.09 \%)$ and acid value $(2.27 \pm 0.17 \mathrm{mgKOH} / \mathrm{g})$ of $Z$. mauritiana seed oil reported in this study is an indication of low hydrolysis of triglyceride and thus would enhance the shelf life and storage stability of the oil. The value recorded in this study is lower than the free fatty acids and the acid value of $0.39 \%$ and $0.64 \mathrm{mg}$ of $\mathrm{KOH} / \mathrm{g}$ respectively reported for L. kerstingii seed oil [2].

The iodine value of Z. mauritiana seed oil $(66.74 \pm 4.29 \mathrm{~g} / 100 \mathrm{~g})$ is similar to $60.72 \mathrm{~g}$ of /100 g reported for L. kerstingii seed oil [2], $65.90 \mathrm{~g}$ of $/ 100 \mathrm{~g}$ reported for that of Moringa oleifera Lam. oil but lower than iodine values of cotton, olive oil, groundnut, and sunflower oils, which ranged from 86 to $145 \mathrm{~g}$ of /100 g of oil [23]. The relatively low iodine value implies low nutritional value, thus implying that Z. mauritiana seed oil is more nutritional than the cotton, olive oil, groundnut, and sunflower oils. Furthermore, the iodine value reported in this study suggests that the Z. mauritiana seed oil is relatively stable upon thermal degradation when used for frying or upon storage with respect to oxidation. The peroxide value of $2.22 \pm 0.12 \mathrm{mmol} / \mathrm{Kg}$ recorded in this study is below the 10 meq. $\mathrm{O}_{2} / \mathrm{kg}$ of oil allowed for crude oils by Codex Alimentarius Committee [24,25].

\section{Conclusion}

The research work indicated thatZ. mauritiana seed oil exhibited a desirable characteristic for nutritional and industrial application. The seed oil has great potential for the use of Z. mauritiana seed oil for both domestic and industrial uses instead of depending solely on palm oil and peanut oil that are scarce and costly.

\section{Acknowledgement}

None.

\section{Conflict of Interest}

No conflict of interest.

\section{References}

1. United Nations (2016) World Population Prospects.

2. Ouilly JT, Bazongo P, Bougma A, Kaboré N, Lykke AM, et al. (2017) Chemical Composition, Physicochemical Characteristics, and Nutritional Value of Lannea kerstingii Seeds and Seed Oil. Journal of Analytical Methods in Chemistry, 6p.

3. FAO (2012) World Agriculture towards 2030/2050: the 2012 Revision. ESA Working Paper 12-03, FAO, Rome, Italy.

4. Sharma M, Gupta SK, Mondal AK (2012) Production and trade of major world oil crops. in Technological Innovations in Major World Oil Crops: Breeding, SK Gupta, Ed., pp. 1-11, New York, NY, USA.

5. Huwale TD (1985) Pollen studies in ziziphus Mauritian cultivars. Annals of Arid zone Journal 1: 47-50.

6. Upadhyay S, Upadhyay P, Ghosh AK, Singh V (2012) Ziziphus Mauritiana: A Review On Pharmacological Potential Of This Underutilized Plant International Journal of Current Research and Review 4(3): 141-144.
7. Wadekar RE (2008) Effect of Ziziphus maurtiana leaf extract on phagocytosis by human neutrophils Journal of Pharmacy Research 1: $1-7$.

8. Bhatia A, Mishra T (2009) Free radical scavenging activity and inhibitory responces of ziziphus maurtiana seed extract on alcohol induced oxidative. An international forum for Evidence Based Practices 1: 8.

9. Mishra T, Kullar N, Bhatia A (2011) Anticancer potential of Aqueous ethanol seed extract of Ziziphus maurtiana against cancer cell lines and Ehrlich Ascites Carcinoma. Evidence Based Complementary And Aleternative medicines 1: 1-8

10. Dahiru D, Sini JM, John A (2006) Africa L Antidiarrhoeal activity of Ziziphus maurtiana root extract in rodents. African Journal of Biotechnology 5: 1-10.

11. Bhatia A, Mishra T (2010) Hypoglycemic activity of Ziziphus maurtiana aqueous ethanol seed extract in alloxan induced diabetic mice. Pharmaceutical biology 48: 604 .

12. Panchal S, Panchal K, Vyas N, Modi K, Patel V, et al. (2010) Antiulcer Activity of Methanolic Extract of Zmauritiana stem Bark. International Journal of Pharmacognosy and Phytochemical Research 2(3): 6-11.

13. Abalaka ME, Daniyan SY, Mann A (2010) Evaluation of the antimicrobial activities of two Ziziphus species. ZmauritianaL and Ziziphus spinachristi L. on some microbial pathogens. African Journal of Pharmacy and Pharmacology 4(4):135-139.

14. Panomwan P, Kanlaya L, Samran P, Palangpon K, Apichart S, et al. (2011) Antiplasmodial and antimycobacterial cyclopeptide alkaloids from the root of Ziziphus mauritiana. Phytochemistry 72: 909-915.

15. AOCS (2003) Official Methods and Recommended Practices of the American Oil Chemists' Society, AOCS Press, Champaign, IIl, USA, 6th edition.

16. Shaba EY, Ndamitso MM, Mathew JT, Etsunyakpa MB, Tsado AN, et al. (2015) Nutritional and anti-nutritional composition of date palm (Phoenix dactylifera L.) fruits sold in major markets of Minna Niger State, Nigeria. Afr J Pure Appl Chem 9(8): 167-174.

17. Omueti O, Bolanle O, Olayinka J Olukayode A (2009) Functional Properties of Complementary Diets Developed from Soybean (Glycine max), Groundnut (Arachis hypogea) and Crayfish (Macro brachium spp.). Elect J Environ Agric Food Chem 8(8): 563 -573.

18. Fagbemi TN (1999) Effect of blanching and ripening on functional properties of plantain (Musa aab) flour Pts Food Hum Nutr 54: 261-269.

19.Zaku SG, Aguzue OC, Thomas SA, Barminas JT (2009) Studies on the functional properties and the nutritive quality of amura plant starch (Tacca involucrate) a wild tropical plant. Afr J Food Sci 3(10): 320-322.

20. Arawande JO, Borokin FB (2010) Comparative study on chemical composition and functional properties of three Nigerian legumes (Jack beans, pigeon pea and cowpea), J Emerging Trends in Engineering and Applied Sciences (JETEAS) 1(1): 89-95.

21. Murthy HN, Joseph KS, Madiwal A, Gerald DR, Badiger M, et al. (2017) Physicochemical Characteristics of the Seed and Seed Oil of the Potentially Medicinal Plant Ziziphus oenoplia. Journal of Dietary Supplements 14(6): 691-696.

22. Gunstone F (2004) The chemistry of oils and fats: Sources, composition, properties and uses. Hoboken, NJ: Wiley Blackwell.

23. Firestone D (1997) Physical and Chemical Characteristics of Oils, Fats and Waxes, AOCS Press, Champaign, IIl, USA.

24. Codex Alimentarus, Codex (2009) Standard for Edible Fats and Oils Not Covered by Individual Standards. CODEX STAN 19-1981, Rev. 2-1999, Codex Alimentarius, Rome, Italy.

25. Djenontina TS, Wottoa VD, Avlessia F, Lozanob P, Sohounhlouéa DKC et al. (2012) Composition of Azadirachta indica and Carapa procera (Meliaceae) seed oils and cakes obtained after oil extraction. Ind Crops Prod 38: 39-45. 